\title{
Role of Iron in Synthetic Tetrahedrites Revisited
}

Daria I. Nasonova ${ }^{1}$, Igor A. Presniakov ${ }^{1}$, Alexei V. Sobolev ${ }^{1}$, Valeriy Yu. Verchenko ${ }^{1,2}$, Alexander A. Tsirlin ${ }^{2,3}$, Zheng $\mathrm{Wei}^{4}$, Evgeny V. Dikarev ${ }^{4}$, and Andrei V. Shevelkov ${ }^{1, *}$

${ }^{1}$ Department of chemistry, Lomonosov Moscow State University, 119991 Moscow, Russia

${ }^{2}$ National Institute of Chemical Physics and Biophysics, 12618 Tallinn, Estonia

${ }^{3}$ Experimental Physics VI, Center for Electronic Correlations and Magnetism, Institute of Physics, University of Augsburg, 86135 Augsburg, Germany

${ }^{4}$ Department of Chemistry, University at Albany, 12222 Albany, NY, USA

* corresponding author, e-mail: shev@inorg.chem.msu.ru

\begin{abstract}
The valence state of iron in $\mathrm{Cu}_{12-\mathrm{x}} \mathrm{Fe}_{\mathrm{x}} \mathrm{Sb}_{4} \mathrm{~S}_{13}$ tetrahedrites have been revisited by the combination of the crystallographic results, Mössbauer spectroscopy, and magnetization measurements. The crystal structure solution for $\mathrm{Cu}_{11.0} \mathrm{Fe}_{1.0} \mathrm{Sb}_{4} \mathrm{~S}_{13}$ (space group $I \overline{4} 3 m, a=$ $10.3253(12), z=2, R=0.011)$ proved that iron substitutes for copper only in the $\mathrm{Cu} 1$ position. At the iron content of $x=0.8,1.0$, and 1.2, the presence of two nonequivalent and noninteracting $\mathrm{Fe}^{3+}$ cations was inferred from Mössbauer spectra. At higher levels of substitution $(x=1.5$ and 2.0), room-temperature Mössbauer spectra indicate the electron hopping between part of $\mathrm{Fe}^{3+}$ and $\mathrm{Fe}^{2+}$ centers, whereas the rest of iron atoms exists as valence-localized $\mathrm{Fe}^{3+}$ and $\mathrm{Fe}^{2+}$ cations. Electron transfer is frozen out at $77 \mathrm{~K}$, where a combination of two $\mathrm{Fe}^{3+}$ sites and one high-spin $\mathrm{Fe}^{2+}$ site is observed. Paramagnetic effective moments extracted from the magnetic susceptibility data point at the $\mathrm{Fe}^{3+}$ state of iron at $x=0.8$, while a mixture of $\mathrm{Fe}^{2+}$ and $\mathrm{Fe}^{3+}$ is presumed in the samples with higher $\mathrm{Fe}$ content.
\end{abstract}

Keywords: tetrahedrite, iron, crystal structure, Mössbauer spectroscopy, electron hopping 


\section{Introduction}

As the efficiency of current state-of-art thermoelectric materials has reached its limit, new ideas for the pursuit of better thermoelectrics are emerging. Thus, the families of semiconductors and semimetals based on complex tellurides, skutterudites, clathrates and various nanostructured materials were intensively investigated, bringing about new and exciting compounds with remarkable thermoelectric properties [1-4]. The unexpected discovery of high thermoelectric efficiency in synthetic and natural tetrahedrites opened a new direction in the search for thermoelectric materials of new generation $[5,6]$. Tetrahedrites are a family of compounds with a general formula $\mathrm{Cu}_{12-\mathrm{x}} \mathrm{M}_{\mathrm{x}} \mathrm{Sb}_{4} \mathrm{~S}_{13}(\mathrm{M}=\mathrm{Fe}, \mathrm{Co}, \mathrm{Ni}, \mathrm{Mn}, \mathrm{Zn})$. They are easy to fabricate, do not contain toxic or rare elements, and their dimensionless thermoelectric figure-of-merit, ZT, reaches a value of 1.13 within the mid-temperature range [7]. Combined, the latter properties make tetrahedrites excellent candidates for creation of thermoelectric materials for automotive power generation [7-9].

Tetrahedrites containing Mn or Fe display the highest figure-of-merit [7], although the valence state of the substituting cation in these materials is different. It was demonstrated that iron is distinct from the other dopants. Whereas all other substituting $3 d$ metals, including manganese, form the $\mathrm{M}^{2+}$ cations, the oxidation state of iron depends on the level of substitution [10]. It is generally believed $[8,10,11]$ that in the $\mathrm{Cu}_{12-\mathrm{x}} \mathrm{Fe}_{\mathrm{x}} \mathrm{Sb}_{4} \mathrm{~S}_{13}$ series, $\mathrm{Fe}^{3+}$ forms until $x$ reaches 1 , while $\mathrm{Fe}^{3+}$ and $\mathrm{Fe}^{2+}$ coexist up to the maximum doping level of $x=2$, at which $\mathrm{Fe}^{2+}$ is present exclusively. According to this model, one assumes that the parent compound $\mathrm{Cu}_{12} \mathrm{Sb}_{4} \mathrm{~S}_{13}$, formulated as $\left(\mathrm{Cu}^{+}\right)_{10}\left(\mathrm{Cu}^{2+}\right)_{2}\left(\mathrm{Sb}^{3+}\right)_{4}\left(\mathrm{~S}^{2-}\right)_{13}$, transforms into $\left(\mathrm{Cu}^{+}\right)_{11}\left(\mathrm{Cu}^{2+}\right)_{1}\left(\mathrm{Sb}^{3+}\right)_{4}\left(\mathrm{~S}^{2-}\right)_{13}$ upon substitution of one iron atom for copper with a concomitant change in the oxidation state of one copper atom from +2 to +1 . Further substitution of iron for copper leads to a decrease in the number of $\mathrm{Fe}^{3+}$ atoms and appearance of $\mathrm{Fe}^{2+}$. For instance, at $x=1.5$ the formula reads as $\left(\mathrm{Cu}^{+}\right)_{10.5}\left(\mathrm{Fe}^{3+}\right)_{0.5}\left(\mathrm{Fe}^{2+}\right)_{1}\left(\mathrm{Sb}^{3+}\right)_{4}\left(\mathrm{~S}^{2-}\right)_{13}$. Finally, at $x=2$ only $\mathrm{Fe}^{2+}$ exists suggesting $\left(\mathrm{Cu}^{+}\right)_{10}\left(\mathrm{Fe}^{2+}\right)_{2}\left(\mathrm{Sb}^{3+}\right)_{4}\left(\mathrm{~S}^{2-}\right)_{13}$ formulation. The analysis of the literature data on the crystal structure and various properties of pristine and Fe-substituted tetrahedrites [8-16] makes us believe that the above description is unrealistic or, at least, oversimplified. In particular, the cubic unit cell parameter increases linearly with iron content, though $\mathrm{Fe}^{3+}$ is smaller than copper for which it substitutes $[8,9]$, and the hyperfine parameters of Mössbauer spectra do not match well with the values expected for high-spin iron tetrahedrally coordinated by sulfur atoms $[10,11]$. Taking these considerations into account, we have undertaken a comprehensive study of Fe-substituted tetrahedrites by means of X-ray 
crystallography, Mössbauer spectroscopy, and magnetization measurements in order to reexamine the role and the valence state of iron in the $\mathrm{Cu}_{12-\mathrm{x}} \mathrm{Fe}_{\mathrm{x}} \mathrm{Sb}_{4} \mathrm{~S}_{13}$ compounds.

In this paper, we present the results of the complex study of iron-substituted tetrahedrites $\mathrm{Cu}_{12-\mathrm{x}} \mathrm{Fe}_{\mathrm{x}} \mathrm{Sb}_{4} \mathrm{~S}_{13}$ as well as discuss the role of iron and the relevance of the proposed distribution of the oxidation states in $\mathrm{Cu}_{12-\mathrm{x}} \mathrm{Fe}_{\mathrm{x}} \mathrm{Sb}_{4} \mathrm{~S}_{13}$. We also put forward new, hitherto unexplained properties of these materials.

\section{Experimental}

\subsection{Starting materials}

Elemental Fe (powder, $99 \%$ ), Sb (pieces, $99.999 \%$ ), $\mathrm{CuO}(99.9 \%)$, and elemental S were used as starting materials for the synthesis. Copper was obtained by heating $\mathrm{CuO}$ under hydrogen flow. Sulfur was gently heated slightly above its melting point under dynamic vacuum for complete water removal. The purity of all reagents was controlled by powder Xray diffraction.

\subsection{Synthesis}

$\mathrm{Cu}_{12-\mathrm{x}} \mathrm{Fe}_{\mathrm{x}} \mathrm{Sb}_{4} \mathrm{~S}_{13}(x=0,0.5,0.8,0.9,1.0,1.1,1.2,1.3,1.5$, and 2.0) compounds were prepared by a standard ampoule technique generally following the procedure described in the literature [5]. In brief, the mixtures of starting materials were sealed in evacuated quartz ampules under a vacuum of $2 \times 10^{-2}$ Torr. Ampules were heated to $973 \mathrm{~K}$, annealed at this temperature for $3 \mathrm{~h}$, slowly cooled down to $823 \mathrm{~K}$ in $30 \mathrm{~h}$, and finally cooled down to room temperature in a switched-off furnace. The reaction products were finely ground in agate mortar and pressed into pellets at a pressure of 80-100 bar at room temperature. These pellets were sealed in evacuated quartz ampules and annealed at $773 \mathrm{~K}$ for $25 \mathrm{~h}$, followed by switching off the furnace and cooling down to room temperature. For each composition, 3 to 5 samples were synthesized in parallel experiments under the same conditions to ensure reproducibility. The resulting samples were finely ground and used for further investigations.

\subsection{X-ray Powder Diffraction and Energy-Dispersive X-ray Spectroscopy}

Phase composition was investigated by a standard X-ray technique using a STADI-P powder diffractometer (Stoe, $\mathrm{Cu} \mathrm{K}_{\alpha 1}$ radiation, Ge monochromator, $\lambda=1.540598 \AA$ ). The program package STOE WinXPOW was used for data processing. Unit cell parameters for each composition were calculated for 3-5 different synthetic batches and averaged. Elemental composition was determined using a JSM JEOL scanning electron microscope operated at 30 $\mathrm{kV}$ and equipped with an EDX detection system INCA x-Sight. Pure elemental Co was used as a standard. The data were collected from 10 points for each sample and then averaged. 
Uniform distribution of elements across the sample was confirmed by mapping (see Supporting Information, Figure S1).

\subsection{Crystal Structure Investigation}

A suitable single crystal was selected from the product of the first annealing step of the composition $\mathrm{Cu}_{11.0} \mathrm{Fe}_{1.0} \mathrm{Sb}_{4} \mathrm{~S}_{13}$. Data were collected at $100 \mathrm{~K}$ on a Bruker D8 VENTURE with PHOTON 100 CMOS detector system equipped with a Mo-target X-ray tube. A frame width of $0.50^{\circ}$ and an exposure time of $15 \mathrm{~s} /$ frame were employed for data collection. Data reduction and integration were performed with the Bruker software package SAINT. Data were corrected for absorption effects using the empirical methods (multi-scan) as implemented in SADABS. The structure was solved and refined using SHELXTL programs. Direct methods were used to solve the crystal structure in the space group $I \overline{4} 3 m$ (No. 217) in accordance with the literature data [15]. The crystal structure was refined with anisotropic thermal parameters for all atoms, which resulted in $R=0.011$. Data collection and refinement parameters are listed in Table 1, atomic parameters in Table 2, and interatomic distances and bond angles in Table 3. Details of the crystal structure refinement are given and discussed in the Results and Discussion section.

\subsection{Mössbauer spectroscopy}

${ }^{57} \mathrm{Fe}$ Mössbauer spectra were recorded at 77 and $300 \mathrm{~K}$ using a conventional constantacceleration spectrometer MS-1104Em in the transmission geometry. A radiation source ${ }^{57} \mathrm{Co}(\mathrm{Rh})$ was kept at room temperature. All isomer shifts are referred to $\alpha$-Fe at $298 \mathrm{~K}$. Experimental spectra were processed and analyzed using methods of spectral simulations implemented in the SpectrRelax program [17].

\subsection{Magnetic properties}

Magnetization was measured with the VSM setup of the Physical Property Measurement System (PPMS, Quantum Design) in external magnetic fields of 0.1, 1, 2 and 5 $\mathrm{T}$ in the temperature range from 2 to $380 \mathrm{~K}$, using pellets prepared by pressing finely ground polycrystalline samples at a pressure of 80-100 bar at room temperature.

\section{Results and discussion}

\subsection{Synthesis and homogeneity range}

Powder XRD patterns for all obtained samples can be indexed in a cubic bodycentered lattice with the unit cell parameters $a$ ranging from 10.320 to $10.378 \AA$. Careful inspection of the patterns showed that at low $(x=0$ and 0.5$)$ and high $(x=1.5$ and 2.0) iron content peaks of a secondary phase $\mathrm{Cu}_{3} \mathrm{SbS}_{4}$ appear reproducibly (see Supporting Information, Figure S2). This observation agrees well with the previous work by Tatsuka and 
Marimoto [18]. They investigated phase relations in the quaternary $\mathrm{Cu}-\mathrm{Fe}-\mathrm{Sb}-\mathrm{S}$ system and found that for $x=0-0.5$ the stoichiometric compositions do not belong to the homogeneity range of tetrahedrite. Instead, tetrahedrite coexists with $\mathrm{Cu}_{3} \mathrm{SbS}_{4}$ at these iron concentrations. For $x=1.5-2.0$, the same authors also observed certain deviations from the stoichiometric composition and proposed that not only $\mathrm{Cu}_{3} \mathrm{SbS}_{4}$, but also $\mathrm{Cu}_{5} \mathrm{FeS}_{4}$ appears as a side product. The latter compound was not observed in our work, though. As the amount of $\mathrm{Cu}_{3} \mathrm{SbS}_{4}$ impurity exceeds $3 \mathrm{wt} \%$ for the samples with $x=0$ and 2.0, we do not consider their unit cell parameters reliable, and therefore show only the unit cell parameters for compounds with $x=$ $0.5-1.5$ in Figure 1. The cubic unit cell parameter linearly increases with increasing $x$, in good agreement with the literature data, but contradicting the change in the ionic radii upon substitution of $\mathrm{Fe}$ for $\mathrm{Cu}$, provided that the $3+$ state is assumed for iron according to the literature data for all compositions with $x \leq 1.0[8,10]$. Indeed, if $\mathrm{Cu}^{2+}$ is replaced by $\mathrm{Fe}^{3+}, \mathrm{a}$ decrease in the unit cell parameter by more than $10 \%$ is expected from the comparison of the ionic radii for the high-spin state in the tetrahedral coordination: $\mathrm{Cu}^{+}, 0.60 \AA$; $\mathrm{Cu}^{2+}, 0.57 \AA$; $\mathrm{Fe}^{2+}, 0.63 \AA$; and $\mathrm{Fe}^{3+}, 0.49 \AA$ [19].

\subsection{Crystal structure refinement and description}

The solution of the crystal structure by direct methods revealed five positions in the space group $I \overline{4} 3 m$ occupied by copper, antimony, and sulfur, viz. $\mathrm{Cu} 1$ in $12 d, \mathrm{Cu} 2$ in $12 e, \mathrm{Sb}$ in $8 c, \mathrm{~S} 1$ in $24 g$ and $\mathrm{S} 2$ in $2 a$. The analysis of the atomic displacement parameters (ADP's) enabled us to notice two important features. First, the $\mathrm{Cu} 1$ atom, which has a tetrahedral environment of sulfur atoms, displays a rather high ADP. Consequently, this position was refined assuming mixed occupancy by iron and copper, which reduced the ADP to reasonable values. Second, the $\mathrm{Cu} 2$ atom, which resides in the center of a sulfur triangle, exhibits a significantly elongated displacement ellipsoid oriented perpendicular to the triangular plane. A careful inspection of the difference Fourier map revealed that the $\mathrm{Cu} 2$ position is split and thus better described by an atom in the $24 \mathrm{~g}$ site with $50 \%$ occupancy. At the later stages of refinement, the occupancy factors for antimony and sulfur atoms were refined and converged to exactly $100 \%$ each. After that, the $\mathrm{Cu}$ :Fe ratio was refined for the $\mathrm{Cu} 1$ position and converged to $81(2): 19(2)$. It was further fixed at 83:17 according to the experimental composition. Finally, the crystal structure was refined in an anisotropic approximation leading to $R=0.011$ and to the atomic parameters listed in Table 2 .

A view of the crystal structure of $\mathrm{Cu}_{11} \mathrm{FeSb}_{4} \mathrm{~S}_{13}$ is given in Figure 2. It is based on a three-dimensional framework composed of $\left[\mathrm{Cu} 1 / \mathrm{Fe} 1(\mathrm{~S} 1)_{4}\right]$ tetrahedra that share all vertices. This framework contains cavities hosting the $\left[\mathrm{Cu} 2(\mathrm{~S} 1)_{2} \mathrm{~S} 2\right]$ and $\left[\mathrm{Sb}(\mathrm{S} 1)_{3}\right]$ pyramidal units. 
These units are centered at the S2 atom forming a cluster depicted in Figure 3. Since the $\mathrm{Cu} 2$ atom does not sit in the plane of the sulfur triangle, it moves closer to the $\mathrm{Sb}$ atom to achieve the $\mathrm{Cu} 2-\mathrm{Sb}$ distance of $3.17 \AA$. Furthermore, the separation between the two neighboring $\mathrm{Cu} 2$ sites is only $0.47 \AA$, which indicates that only one of the neighboring positions is occupied, and the occupied and vacant positions alternate within a cluster in one out of four possible regular ways, as shown in Figure 3. However, such an alternation is local and does not result in any visible superstructure. Consequently, the $\mathrm{Sb}$ atom may form up to three bonds with the $\mathrm{Cu} 2$ atoms, and the probability that a given antimony atom does not form $\mathrm{Sb}-\mathrm{Cu} 2$ bonds is only 1/8. Therefore, the description of the $\left[\mathrm{Sb}(\mathrm{S} 1)_{3}\right]$ unit as a pyramid with an $\mathrm{Sb}^{3+}$ atom bearing a stereochemically active lone pair is generally incorrect. Rather, for the majority of the $\mathrm{Sb}$ atoms this lone pair is involved in interaction with the $\mathrm{Cu} 2$ atoms, similar to the situation previously observed for $\mathrm{Sn}^{2+}$ cations in cationic clathrates [20].

Given the high accuracy of the crystal structure refinement, we conclude that iron mixes with copper only at the $\mathrm{Cu} 1$ site, which agrees perfectly with the neutron diffraction data of Andreasen et al. [14] and consents with the propensity of iron to have the tetrahedral coordination in various sulfides [21]. The splitting of the $\mathrm{Cu} 2$ atomic position results in the formation of $\mathrm{Sb}-\mathrm{Cu} 2$ bonds, in full agreement with the literature data $[9,12]$. Moreover, the alternation of occupied and vacant $\mathrm{Cu} 2$ positions within a cluster centered at the $\mathrm{S} 2$ atom may well lead to a random sequence of clusters, where all $\mathrm{Sb}$ atoms form from one to three bonds with the $\mathrm{Cu} 2$ atoms, and those clusters where $\mathrm{Sb}$ atoms have the stereoactive lone pair. We also note that the $\mathrm{Cu} 2$ atom in the $24 g$ position retains a slightly elongated displacement ellipsoid pointing towards the $\left[\mathrm{S}_{3}\right]$ triangle plane. This effect was previously noticed in the literature for pristine [12] and Mn-substituted tetrahedrites [9]. For these compounds, two scenarios were proposed - the anharmonic displacement or rattling of the $\mathrm{Cu} 2$ atoms, both effects being responsible for low thermal conductivity observed experimentally. Finally, all positions except that of $\mathrm{Cu} 2$ are fully occupied, thus leaving no space for vacancies.

\subsection{Mössbauer spectroscopy}

${ }^{57} \mathrm{Fe}$ Mössbauer spectra were recorded for the samples with $x=0.8,1.0,1.2,1.5$, and 2.0. First four samples were chosen as they belong to the homogeneity range of the Fe-bearing tetrahedrite [18] and were proved to be phase-pure. The latter sample was included as a reference to follow the development of the hyperfine parameters and their intensities. Though this sample was not phase-pure, it was not contaminated by any Fe-contained impurities.

The ${ }^{57} \mathrm{Fe}$ Mössbauer spectra of all $\mathrm{Cu}_{12-x} \mathrm{Fe}_{x} \mathrm{Sb}_{4} \mathrm{~S}_{13}$ compositions acquired in this work at $300 \mathrm{~K}$ can be subdivided into two groups. The first group comprises spectra for the samples 
with $x=0.8,1.0$, and 1.2 (Figure 4). Each of those can be described as a superposition of two quadrupole doublets, $\mathrm{Fe} 1$ and $\mathrm{Fe} 2$, characterized by different values of isomer shifts $\delta$ and quadrupole splitting $\Delta$, thus corresponding to two types of iron atoms. The minor component $\mathrm{Fe}$, which provides about $15 \%$ of the spectral area, exhibits the average values of the isomer shift, $\left\langle\delta_{1}\right\rangle \approx 0.17 \mathrm{~mm} / \mathrm{s}$, expected for the high-spin $\mathrm{Fe}^{3+}$ cation in environment of sulfur atoms, though its quadrupole splitting $\left\langle\Delta_{1}\right\rangle \approx 0.69 \mathrm{~mm} / \mathrm{s}$ (Table 4) is quite high for the symmetric sulfur coordination $[11,21]$. At the same time, the major $\mathrm{Fe} 2$ component of the spectra $\left(I_{2} \approx 85 \%\right)$ has a noticeably larger isomer shift than typically observed for $\mathrm{Fe}^{3+}$ sulfides $(0.15-0.25 \mathrm{~mm} / \mathrm{s})$, whereas its quadrupole splitting is typical for the high-spin $\mathrm{Fe}^{3+}$ in symmetric tetrahedral environment $[11,22]$. Although the hyperfine parameters for both components of the spectra could be crudely ascribed to $\mathrm{Fe}^{3+}$, we note that these parameters are not typical for the high-spin $\mathrm{Fe}^{3+}$ in symmetrical tetrahedral environment of four sulfur atoms. We also note that the spectrum acquired at $77 \mathrm{~K}$ for the compound with $x=1$ (not shown) shows virtually no changes in the line shape and hyperfine parameters compared to those observed at $300 \mathrm{~K}$.

Therefore, we conclude that first, no sign of $\mathrm{Fe}^{2+}$ is observed up to the composition $x=$ 1.2 , in contradiction with the accepted model of the charge distribution (see Introduction for details), according to which $20 \%$ of iron atoms should be in the $\mathrm{Fe}^{2+}$ state at $x=1.2$ and thus should be easily detectable by this method. Second, the coexistence of two components of the spectra observed in our work has never been reported in the literature. For instance, Makovicky et al. described the spectrum of $\mathrm{Cu}_{11} \mathrm{Fe}_{1} \mathrm{Sb}_{4} \mathrm{~S}_{13}$ as a single quadrupole doublet with $\delta=0.31 \mathrm{~mm} / \mathrm{s}$ and $\Delta=0.29 \mathrm{~mm} / \mathrm{s}$ [10], which might be explained by a low signal intensity. We note that the crystallographic data obtained in this work and those reported in the literature [14] explicitly indicate that iron occupies only one crystallographic position, partially substituting $\mathrm{Cu} 1$. Therefore, the appearance of two quadrupole doublets stems from the local nonequivalence of iron. Pairing of iron centers through a sulfur bridge, clusterization of $\mathrm{Fe}$ atoms, or their selected interaction with copper atoms are likely reasons for such nonequivalence. We should stress that the intensity of Fe1 quadrupole doublet for all three compounds is more than $15 \%$, which is too large to be associated with the presence of an Xray undetected $\mathrm{Fe}$-contained side phase. In addition, hyperfine parameters of this quadrupole doublet for all compositions are the same, thus, we cannot link it with the presence of the impurity. Therefore, we conclude that the observed spectra represent intrinsic properties of the studied compositions. 
The ${ }^{57} \mathrm{Fe}$ Mössbauer spectra of $\mathrm{Cu}_{10.5} \mathrm{Fe}_{1.5} \mathrm{Sb}_{4} \mathrm{~S}_{13}$ and $\mathrm{Cu}_{10} \mathrm{Fe}_{2} \mathrm{Sb}_{4} \mathrm{~S}_{13}$ at $300 \mathrm{~K}$ are considerably more complex (Figure 5) and can be roughly described as a superposition of three quadrupole doublets $\mathrm{Fe} 1, \mathrm{Fe} 2$ and $\mathrm{Fe} 3$. The hyperfine parameters of the $\mathrm{Fe} 1$ and $\mathrm{Fe} 2$ doublets (Table 5) are close to those for the samples $\mathrm{Cu}_{12-\mathrm{x}} \mathrm{Fe}_{\mathrm{x}} \mathrm{Sb}_{4} \mathrm{~S}_{13}$ with $x=0.8,1.0$, and 1.2. Both $\mathrm{Fe} 2$ and $\mathrm{Fe} 3$ doublets have very broad components. Such a broadening can be related to the relaxation effects due to electron hopping [11]. The relaxation process is most obvious in the case of $\mathrm{Cu}_{10.5} \mathrm{Fe}_{1.5} \mathrm{Sb}_{4} \mathrm{~S}_{13}$ (Figure 5), where the $\mathrm{Fe} 2$ doublet and one of the $\mathrm{Fe} 3$ lines are not well resolved, and a continuous absorption appears between the right-hand $\mathrm{Fe} 2$ $\left(v_{2} \approx 0.6 \mathrm{~mm} / \mathrm{s}\right)$ and Fe3 $\left(v_{3} \approx 2.2 \mathrm{~mm} / \mathrm{s}\right)$ peaks (see Figure 5$)$. The fact that the continuous absorption is the strongest for $\mathrm{Cu}_{10.5} \mathrm{Fe}_{1.5} \mathrm{Sb}_{4} \mathrm{~S}_{13}$, where the amounts of $\mathrm{Fe}^{3+}$ and $\mathrm{Fe}^{2+}$ are comparable, indicates that this effect must arise from the electron exchange between the $\mathrm{Fe}^{2+}$ and $\mathrm{Fe}^{3+}$ ions. Apparently, this exchange is a thermally activated process, as deduced from the disappearance of the continuous absorption upon decreasing the temperature. Indeed, the spectra of both samples at $T=77 \mathrm{~K}$ can be described as a superposition of three "discrete" quadrupole doublets (Figure 6) corresponding to the $\mathrm{Fe}^{3+}$ ions (Fe1 and $\mathrm{Fe} 2$ ) and the highspin divalent $\mathrm{Fe}^{2+}$ ions (Fe3) with hyperfine parameters summarized in Table 6. The profile of Mössbauer spectra for two $\mathrm{Fe}^{2+}$ and $\mathrm{Fe}^{3+}$ charge states is expected to be very sensitive to the difference between their resonance frequencies $\left(\omega_{\mathrm{Fe} 3}-\omega_{\mathrm{Fe} 2}\right) \approx 10^{8} \mathrm{~s}^{-1}$, which corresponds to $\left(v_{3}-v_{2}\right) \approx 1.6 \mathrm{~mm} / \mathrm{s}$ (see Figure 6) and the electron hopping frequency $\left(\omega_{h o p}\right)$ for the $\mathrm{Fe}_{\mathrm{a}}{ }^{2+}-$ $\mathrm{Fe}_{\mathrm{b}}{ }^{3+} \leftrightarrow \mathrm{Fe}_{\mathrm{a}}{ }^{3+}-\mathrm{Fe}_{\mathrm{b}}{ }^{2+}$ reaction. If $\omega_{h o p}<<10^{8} \mathrm{~s}^{-1}$, the Mössbauer spectra are a superposition of individual $\mathrm{Fe}^{2+}$ and $\mathrm{Fe}^{3+}$ subspectra, as observed at $77 \mathrm{~K}$. With increasing temperature, the value of $\omega_{\text {hop }}$ increases, and in a region of $\omega_{\text {hop }}$ around $10^{8} \mathrm{~s}^{-1}$, a strong line broadening leads to the absorption in the entire region extending between the $\mathrm{Fe}^{2+}$ and $\mathrm{Fe}^{3+}$ lines as observed at $300 \mathrm{~K}$ (Figure 5). Further increase of $\omega_{\text {hop }}\left(>10^{8} \mathrm{~s}^{-1}\right)$ is expected to result in a merge of this broad absorption region into one "mixed" $\mathrm{Fe}^{2.5+}$ line with weighted average parameters $(\delta, \Delta)$ of the $\mathrm{Fe}^{2+}$ and $\mathrm{Fe}^{3+}$ subspectra [22, 23].

In order to analyze the experimental Mössbauer spectra taking into account the above relaxation processes, we used a stochastic model given by Tjon and Blume [24] for the description of a spectrum in the presence of stochastic hyperfine fluctuations. Following their procedure, we attempted to simulate the Mössbauer spectra of the $\mathrm{Cu}_{10.5} \mathrm{Fe}_{1.5} \mathrm{Sb}_{4} \mathrm{~S}_{13}$ and $\mathrm{Cu}_{10} \mathrm{Fe}_{2} \mathrm{Sb}_{4} \mathrm{~S}_{13}$ samples using the two-level relaxation processes between $\left(\mathrm{Fe}_{\mathrm{a}}{ }^{2+}-\mathrm{Fe}_{\mathrm{b}}{ }^{3+}\right)_{1} \leftrightarrow$ $\left(\mathrm{Fe}_{\mathrm{a}}{ }^{3+}-\mathrm{Fe}_{\mathrm{b}}{ }^{2+}\right)_{2}$ nuclear energy levels with a relaxation time $\tau=\left(\omega_{\text {hop }}\right)^{-1}$ given by $\tau=$ $\left(\tau_{12} \tau_{21}\right) /\left(\tau_{12}+\tau_{21}\right)$, where $\tau_{12}$ and $\tau_{21}$ stand for the relaxation times for " 1 " to " 2 " and for " 2 " to 
"1" states, respectively. The relative probability for the $\left(\mathrm{Fe}_{\mathrm{a}}{ }^{2+}-\mathrm{Fe}_{\mathrm{b}}{ }^{3+}\right)_{1}$ state is given by $n_{1}=$ $\tau / \tau_{21}$. It is necessary to assume opposite signs for the quadrupole interaction in the $\mathrm{Fe}^{2+}$ and $\mathrm{Fe}^{3+}$ sites and to leave the values of isomer shift and quadrupole splitting as variables. Thus, four parameters $\left\{\delta_{1}, \Delta_{\mathrm{i}}\right\}_{\mathrm{i}=2,3}$ for both iron states, the relaxation time $\tau$ (or the hopping frequency $\omega_{\text {hop }}$ ), and the ratio of probabilities $n_{1} / n_{2}=\omega_{21} / \omega_{12}$ are to be determined to interpret the Mössbauer spectra shown in Figure 5 (the minimum experimental line width $W$ was constrained for all the doublets to $0.25 \mathrm{~mm} / \mathrm{s}$ ). The simulated results are represented by solid lines in Figure 5 and fitting parameters are listed in Table 5.

Comparison of the fitting results at two temperatures (Tables 5 and 6) shows that no additional resonances with temperature-dependent hyperfine parameters as well as no line broadenings, except those which are caused by relaxation, had to be introduced in order to yield satisfactory fits to the experimental data. The isomer shifts $\delta_{2}$ and $\delta_{3}$ show a slight decrease with increasing temperature, as expected from the variation of the second-order Doppler shift [25]. In addition, a slight decrease of the quadrupole splitting $\Delta_{3}$ for the $\mathrm{Fe}^{2+}$ sites with increasing temperature is typical of a valence-contribution-dominated electric field gradient with a temperature dependence determined by the Boltzmann population of the orbital states split by the crystal field. Therefore, our data demonstrate that the $\mathrm{Fe}^{3+}$ ions are involved in the electron hopping with a part of the $\mathrm{Fe}^{2+}$ ions, but no additional change of electron configuration of iron atoms occurs upon changing the temperature.

Within the above model, the best description of the spectra for the compounds with $x=$ 1.5 and 2.0 measured at $300 \mathrm{~K}$ (Figure 5) may be obtained only by taking into account a superposition of individual $\mathrm{Fe} 2$ and $\mathrm{Fe} 3$ components (valence-localized states) along with the continuous absorption (relaxing state), thus implying that the electron exchange process occurs just for part of the $\mathrm{Fe}^{3+}$ and $\mathrm{Fe}^{2+}$ pairs. We attribute the latter to a non-equivalence of the $\mathrm{Fe}_{\mathrm{a}}{ }^{3+/ 2+}$ and $\mathrm{Fe}_{\mathrm{b}}{ }^{3+/ 2+}$ sites, which is expected from the presence of different cations $\left(\mathrm{Cu}^{+}\right.$, $\left.\mathrm{Sb}^{3+}, \mathrm{Fe}^{2+}\right)$ in their local environments. This non-equivalence also manifests itself in the line broadening observed in the $\mathrm{Fe} 2$ pattern for the $\mathrm{Cu}_{10} \mathrm{Fe}_{2} \mathrm{Sb}_{4} \mathrm{~S}_{13}$ sample at $77 \mathrm{~K}$ (Table 6). This non-equivalence can be represented by a difference $U_{0}$ between a pair of two sublevels "1" and "2" (Figure 7). Within the model of a double potential [22], assuming that the electron exchange takes place mainly in isolated $\mathrm{Fe}^{2+}$ and $\mathrm{Fe}^{3+}$ pairs, the relevant parameters are the potential well difference $U_{0}$ and the intervening potential barrier $E_{\mathrm{A}}$ (Figure 7) representing the self-trapping energy due to the local lattice deformation and electrical polarization [23, $24]$. According to this simple model, the number of electron jumps $\left(\mathrm{Fe}_{\mathrm{a}}{ }^{2+}-\mathrm{Fe}_{\mathrm{b}}{ }^{3+}\right)_{1} \leftrightarrow\left(\mathrm{Fe}_{\mathrm{a}}{ }^{3+}-\right.$ $\left.\mathrm{Fe}_{\mathrm{b}}{ }^{2+}\right)_{2}$ from the lower level ("1") to the upper one ("2") is proportional to the thermal fraction 
having sufficient energy to pass the barrier $\left(U_{0}+E_{\mathrm{A}}\right)$ [22]: $\omega_{\text {hop }} \propto \exp \left\{-\left(U_{0}+E_{\mathrm{A}}\right) / k T\right\}$. Upon temperature increase, the condition $\omega_{\text {hop }} \approx 10^{8} \mathrm{~s}^{-1}$ is satisfied for increasing energy $U_{0}$ and the number of $\mathrm{Fe}^{2+} / \mathrm{Fe}^{3+}$ pairs that produce "mixed" spectra with the positions determined by the population fraction, $n_{2} \propto \exp \left\{-U_{0} / k T\right\}$, of the energetically unfavorable site determined by the $U_{0}$ value. This shows that the observation of the continuous absorption finds a natural explanation in the small $\Delta U\left(\Delta U^{*}\right)$ distribution (Figure 7) due to the nonequivalence of iron sites. Interestingly, the width of this distribution, which reflects the degree of perturbation of the electron delocalization, depends on the stoichiometry of the sample.

For a more detailed analysis of the relaxation parameters, the extensive temperaturedependent ${ }^{57} \mathrm{Fe}$ Mössbauer measurements for the samples $\mathrm{Cu}_{12-\mathrm{x}} \mathrm{Fe}_{\mathrm{x}} \mathrm{Sb}_{4} \mathrm{~S}_{13}$ with $1<x \leq 2$ are required. Analysis of such measurements is beyond the scope of this work.

\subsection{Magnetic properties}

To the best of our knowledge, no information on magnetic properties of the $\mathrm{Fe}$ substituted tetrahedrite is available in the literature. In the only parent tetrahedrite studied, a combination of magnetic susceptibility measurements and ESR spectroscopy results confirmed the presence of $\mathrm{Cu}^{2+}$ [26]. However, magnetization data could effectively complement Mössbauer spectra in regard to the valence states of iron. This information is especially important for the samples with lower doping levels, where spectral parameters are somewhat different from those of the reference $\mathrm{Fe}^{3+}$ materials. Figure 8 shows reciprocal magnetic susceptibility of $\mathrm{Cu}_{12-\mathrm{x}} \mathrm{Fe}_{\mathrm{x}} \mathrm{Sb}_{4} \mathrm{~S}_{13}(x=0.8,1.0,1.2)$ plotted as a function of temperature. The $1 / \chi(\mathrm{T})$ dependence reveals Curie-Weiss paramagnetic behavior, and no field dependence is observed. Using the modified Curie-Weiss law $\chi=\chi_{0}+C_{\mathrm{CW}} /\left(T+\theta_{\mathrm{CW}}\right)$, temperature-independent susceptibility $\chi_{0}$, Curie-Weiss temperature $\theta_{\mathrm{CW}}$, and Curie-Weiss constant $C_{\mathrm{CW}}$ for each compound were calculated using the $5 \mathrm{~T}$ data, and the effective paramagnetic moments per one iron atom were obtained.

The $\chi_{0}$ susceptibility is defined as: $\chi_{0}=\chi_{\mathrm{P}}+\chi_{\text {core }}+\chi_{\mathrm{VV}}+\chi_{\mathrm{L}}$, where $\chi_{\mathrm{P}}$ is the Pauli paramagnetic spin susceptibility of conduction electrons, $\chi_{\text {core }}$ is the diamagnetic orbital contribution from the core electrons, $\chi_{\mathrm{VV}}$ is the Van Vleck paramagnetic orbital contribution, and $\chi_{\mathrm{L}}$ is the Landau orbital diamagnetism of the conduction electrons. Taking into account that iron-substituted tetrahedrites demonstrate semiconducting properties, $\chi_{0}$ is mainly determined by $\chi_{\text {core }}$. The values extracted from the experimental data, $\chi_{0}=-7 \cdot 10^{-4},-3 \cdot 10^{-4}$, and $-5 \cdot 10^{-4} \mathrm{emu} / \mathrm{mol}$ for $x=0.8,1.0$ and 1.2 , respectively, are in agreement with the $\chi_{\text {core }}$ value calculated from the literature data [27]: $\chi_{\text {core }}$ is $-6 \cdot 10^{-4} \mathrm{emu} / \mathrm{mol}$ for all investigated samples (the deviation from this value for different compounds is suppressed by rounding 
because of low difference in the iron content). The negative values of the Curie-Weiss temperature, $\theta_{\mathrm{CW}}=-30.9,-36.5$, and $-36.6 \mathrm{~K}$ for $x=0.8,1.0$, and 1.2 , respectively, indicate dominant antiferromagnetic interactions between the iron spins for all investigated compounds. Effective paramagnetic moments are 5.87, 5.67, and 5.55 $\mu_{\mathrm{B}} / \mathrm{Fe}$ for $x=0.8,1.0$, and 1.2 , respectively. Therefore, only $\mathrm{Fe}^{3+}$ with the spin-only effective moment of $5.92 \mu_{\mathrm{B}}(S$ $=5 / 2$ ) is present in the sample with $x=0.8$. The lower effective moments for the samples with higher Fe content imply the mixing of $\mathrm{Fe}^{2+}$ and $\mathrm{Fe}^{3+}$.

We conclude that the magnetic moment per Fe atom changes with nearly the same increment upon going from $x=0.8$ to $x=1.0$ and to $x=1.2$. No abrupt drop of the moment occurs upon crossing the $x=1.0$ value, where, according to the literature (see Introduction), a transition from pure $\mathrm{Fe}^{3+}$ to coexisting $\mathrm{Fe}^{3+}$ and $\mathrm{Fe}^{2+}$ is expected. However, the putative coexistence of $\mathrm{Fe}^{2+}$ and $\mathrm{Fe}^{3+}$ at $x=1.0$ and $x=1.2$ is at odds with the Mössbauer data, where both spectral lines can be ascribed to $\mathrm{Fe}^{3+}$. The origin of this discrepancy is not clear at the moment and requires further investigation.

For comparison, Figure 8 also displays the temperature dependence of reciprocal magnetic susceptibility for the sample with $x=1.5$ at $5 \mathrm{~T}$ external field. While the susceptibility seemingly follows the modified Curie-Weiss law, it demonstrates a strong field dependence (not shown), which was not observed for $x=0.8,1.0$, and 1.2. This may originate in the charge transfer between the iron centers and will be a topic of a separate study.

\section{Conclusions}

Combining the structural data with the results of Mössbauer spectroscopy and magnetization measurements, we propose that the literature model for the $\mathrm{Fe}^{3+}$ and $\mathrm{Fe}^{2+}$ distribution in iron-containing tetrahedrites $\mathrm{Cu}_{12-\mathrm{x}} \mathrm{Fe}_{\mathrm{x}} \mathrm{Sb}_{4} \mathrm{~S}_{13}$ should be amended. The analysis of the crystal structure confirms that iron substitutes copper only in one position, $\mathrm{Cu} 1$, but the Mössbauer spectra provide evidence for two locally nonequivalent iron atoms for all compositions from $x=0.8$ to $x=2.0$. Furthermore, the Mössbauer data suggest that two ranges of $\mathrm{Fe}$ doping level exist. The first one includes $x=1.5$ and $x=2.0$ and can be described by a model assuming electron hopping between the $\mathrm{Fe}^{3+}$ and $\mathrm{Fe}^{2+}$ centers, which freezes out upon cooling down to $77 \mathrm{~K}$. Importantly, such electron hopping takes place between a part of iron centers only, whereas the rest of iron atoms exists as localized $\mathrm{Fe}^{3+}$ and $\mathrm{Fe}^{2+}$ cations. For the compositions with lower iron content, $x=0.8,1.0$, and 1.2, two nonequivalent $\mathrm{Fe}^{3+}$ cations manifest themselves in Mössbauer spectra. Those iron centers do not interact with each other; however, the results of the magnetization measurements suggest that the effective moment per one iron center is somewhat lower than required by a high-spin 
$\mathrm{Fe}^{3+}$ cation. Apparently, an interaction between $\mathrm{Fe}^{3+}$ and copper centers cannot be ruled out, but for $x=1.2$ composition the electroneutrality cannot be achieved by combining only $\mathrm{Fe}^{3+}$ and $\mathrm{Cu}^{+}$; therefore, other explanations should be put forward to account for unusual behavior of iron-bearing tetrahedrites. This is important in light of their thermoelectric properties, especially since the recent report [28] argues that strong coupling of charge carriers and doped spins is accountable for high thermoelectric efficiency of $d$-metal chalcogenides. Further study of the electronic structure and electron correlations in synthetic tetrahedrites is currently underway.

\section{Acknowledgements}

The work in Moscow has been supported by the Russian Science Foundation, grant No.14-13-00089. The work in Tallinn has been supported by the Mobilitas program of the ESF, grant MTT77. The work in Albany has been supported by National Science Foundation, grant No. CHE-1337594. A.A.T. is also grateful for the financial support by the Federal Ministry for Education and Research under the Sofia Kovalevskaya Award of the Alexander von Humboldt Foundation. E.V.D. thanks Civil Research and Development Foundation for the traveling grant FSAX-14-60560-0, which facilitated discussion of this work. 


\section{References}

1. M.G. Kanatzidis, Structural Evolution and Phase Homologies for "Design" and Prediction of Solid-State Compounds, Acc. Chem. Res. 38 (2005) 359-368.

2. Y. Dong, P. Puneet, T.M. Tritt, G.S.Nolas, Crystal structure and high temperature transport properties of $\mathrm{Yb}$-filled p-type skutterudites $\mathrm{Yb}_{\mathrm{x}} \mathrm{Co}_{2.5} \mathrm{Fe}_{1.5} \mathrm{Sb}_{12}$, J. Solid State Chem. 209 (2014) $1-5$.

3. L.D. Zhao, S.H. Lo, Y. Zhang, H. Sun, G. Tan, C. Uher, C. Wolverton, V. P. Dravid, M.G. Kanatzidis, Ultralow thermal conductivity and high thermoelectric figure of merit in $\mathrm{SnSe}$ crystals, Nature 508 (2014) 373-377.

4. A.V. Shevelkov, K. Kovnir, Zintl Clathrates, Struct. Bond. 139 (2011) 97-142.

5. K. Suekuni, K. Tsuruta, M. Kunii, H. Nishiate, E. Nishibori, S. Maki, M. Ohta, A. Yamamoto, M. Koyano, High-performance thermoelectric mineral $\mathrm{Cu}_{12-\mathrm{x}} \mathrm{Ni}_{\mathrm{x}} \mathrm{Sb}_{4} \mathrm{~S}_{13}$ tetrahedrite, J. Appl. Phys. 113 (2013) 043712.

6. X. Lu, D.T. Morelli, Y. Xia, F. Zhou, V. Ozolins, H. Chi, X. Zhou, C. Uher, High performance thermoelectricity in earth-abundant compounds based on natural mineral tetrahedrites, Adv. Energy Mater. 3 (2013) 342-348.

7. J. Heo, G. Laurita, S. Muir, M.A. Subramanian, D.A. Keszler, Enhanced thermoelectric performance of synthetic tetrahedrites, Chem. Mater. 26 (2014) 2047-2051.

8. K. Suekuni, Y. Tomizawa, T. Ozaki, M. Koyano, Systematic study of electronic and magnetic properties for $\mathrm{Cu}_{12-\mathrm{x}} \mathrm{TM}_{\mathrm{x}} \mathrm{Sb}_{4} \mathrm{~S}_{13}(\mathrm{TM}=\mathrm{Mn}, \mathrm{Fe}, \mathrm{Co}, \mathrm{Ni}$, and $\mathrm{Zn})$ tetrahedrite, $\mathrm{J}$. Appl. Phys. 115 (2014) 143702.

9. R. Chetty, P. Kumar, G. Rogl, P. Rogl, E. Bauer, H. Michor, S. Suwas, S. Puchegger, G. Giester, R.C. Mallik, Thermoelectric properties of a Mn substituted synthetic tetrahedrite, Phys. Chem. Chem. Phys. 17 (2015) 1716-1727.

10. E. Macovicky, K. Forcher, W. Lottermoser, G. Amthauer, The role of $\mathrm{Fe}^{2+}$ and $\mathrm{Fe}^{3+}$ in synthetic Fe-substituted tetrahedrite, Miner. Petrol. 43 (1990) 73-81.

11. E. Macovicky, G. Tippelt, K. Forcher, W. Lottermoser, S. Karup-Mǿller, G. Amthauer, Mössbauer study of Fe-bearing synthetic tennantite, Can. Mineral. 41 (2003) 1125-1134.

12. A. Pfitzner, M. Evain, V. Petriček, $\mathrm{Cu}_{12} \mathrm{Sb}_{4} \mathrm{~S}_{13}$ : a temperature-dependent structure investigation, Acta Cryst. B 53 (1997) 337-345.

13. N.E. Johnson, J.R. Craig, J.D. Rimstidt, Crystal chemistry of tetrahedrite, Am. Mineral. 73 (1988) 389-397. 
14. J.W. Andreasen, E. Macovicky, B. Lebech, S. Karup-Mǿller, The role of iron in tetrahedrite and tennantite determined by Rietveld refinement of neutron powder diffraction data, Phys. Chem. Minerals 35 (2008) 447-454.

15 K. Friese, A. Grzechnik, E. Macovicky, T. Balic-Zunic, S. Karup-Mǿller, Crystal structures of iron bearing tetrahedrite and tennantite at 25 and $250^{\circ} \mathrm{C}$ by means of Rietveld refinement of synchrotron data, Phys. Chem. Minerals 35 (2008) 455-465.

16. B.J. Wuensch, The crystal structure of tetrahedrite, $\mathrm{Cu}_{12} \mathrm{Sb}_{4} \mathrm{~S}_{13}$, Z. Kristallogr 119 (1964) 437-453.

17. M.E. Matsnev, V.S. Rusakov, An Application for Mössbauer Spectra Modeling and Fitting, AIP Conf. Proc. 1489 (2012), 178-185.

18. K. Tatsuka, N. Morimoto, Tetrahedrite stability relations in the Cu-Fe-Sb-S system, Am. Mineral. 62 (1977) 1101-1109.

19. R. Dronskowski, Computational Chemistry of Solid State Materials. Wiley-VCH. Weinheim (2005) 294 p.

20. K.A. Kovnir, A.V. Sobolev, I.A. Presniakov, O.I. Lebedev, G. Van Tendeloo, W. Schnelle, Yu. Grin, A.V. Shevelkov, $\mathrm{Sn}_{19.3} \mathrm{Cu}_{4.7} \mathrm{As}_{22} \mathrm{I}_{8}$ : a New Clathrate-I Compound with Transition-Metal Atoms in the Cationic Framework, Inorg. Chem. 44 (2005) 8786-8793.

21. J.B. Goodenough, G.A. Fatseas, Mössbauer ${ }^{57} \mathrm{Fe}$ isomer shift as a measure of valence in mixed-valence iron sulfides, J. Solid State Chem. 41 (1982), 1-22.

22. C. Achim, E.L. Bominaar, R.J. Staples, E. Münck, R.H. Holm, Influence of Extrinsic Factors on Electron Transfer in a Mixed-Valence $\mathrm{Fe}^{2+} / \mathrm{Fe}^{3+}$ Complex: Experimental Results and Theoretical Considerations, Inorg. Chem. 40 (2001) 4389-4403.

23. D.A. Nolet, R.G. Burns, Ilvaite: a study of temperature dependent electron delocalization by the Mössbauer effect, Phys. Chem. Minerals 4 (1979) 221-234.

24. J.A. Tjon, M. Blume, Mössbauer Spectra in a Fluctuating Environment II. Randomly Varying Electric Field Gradients, Phys. Rev. 165 (1968) 456-461.

25. P. Gütlich, E. Bill, A.X. Trautwein, Mössbauer Spectroscopy and Transition Metal Chemistry (Fundamentals and Applications), Springer (2011).

26. F. Di Benedetto, G. P. Bernardini, C. Cipriani, C. Emiliani, D. Gatteschi, M. Romanelli, The distribution of $\mathrm{Cu}(\mathrm{II})$ and the magnetic properties of the synthetic analogue of tetrahedrite: $\mathrm{Cu}_{12} \mathrm{Sb}_{4} \mathrm{~S}_{13}$, Phys. Chem. Minerals 32 (2005) 155-164.

27. G.A. Bain, J.F. Berry, Diamagnetic Corrections and Pascal's Constants, J. Chem. Educ. 85 (2008) 532-536. 
28. R. Ang, A.U. Khan, N. Tsujii, K. Takai, R. Nakamura, T. Mori, Thermoelectricity Generation and Electron-Magnon Scattering in a Natural Chalcopyrite Mineral from a Deep-Sea Hydrothermal Vent, Angew. Chem. Int. Ed. 54 (2015) 12909-12913. 
Table 1. Summary of data collection and refinement parameters for $\mathrm{Cu}_{11.0} \mathrm{Fe}_{1.0} \mathrm{Sb}_{4} \mathrm{~S}_{13}$

\begin{tabular}{|c|c|}
\hline Composition & $\mathrm{Cu}_{11.0} \mathrm{Fe}_{1.0} \mathrm{Sb}_{4} \mathrm{~S}_{13}$ \\
\hline Crystal system & Cubic \\
\hline Space Group & $I \overline{4} 3 m$ \\
\hline$a, \AA$ & $10.3253(12)$ \\
\hline$V, \AA^{3}$ & $1100.8(4)$ \\
\hline$Z$ & 1 \\
\hline$d_{\text {calc }}$ & 5.004 \\
\hline Radiation/wavelength & MoK $\alpha / 0.71073 \AA$ \\
\hline Temperature, $\mathrm{K}$ & $100(2)$ \\
\hline Crystal size, $\mathrm{mm}^{3}$ & $0.12 \times 0.09 \times 0.06$ \\
\hline Color & dark gray \\
\hline Absorption correction & SADABS \\
\hline$\Theta$ range (data collection) & $2.79-30.54$ \\
\hline Range of $h, k, l$ & $\begin{aligned}-14 & \rightarrow h \rightarrow 14 \\
-14 & \rightarrow k \rightarrow 14 \\
-14 & \rightarrow l \rightarrow 14\end{aligned}$ \\
\hline$R_{\mathrm{int}}$ & 0.0744 \\
\hline$R / R_{\mathrm{w}}(I>2 \sigma(I))$ & $0.0116 / 0.0238$ \\
\hline Flack parameter $x$ & $-0.004(17)$ \\
\hline GoF & 1.205 \\
\hline$\Delta r_{\max }\left(\mathrm{e} / \mathrm{A}^{-3}\right)$ & $0.563 /-0.324$ \\
\hline
\end{tabular}


Table 2. Atomic parameters in the crystal structure of $\mathrm{Cu}_{11.0} \mathrm{Fe}_{1.0} \mathrm{Sb}_{4} \mathrm{~S}_{13}$

\begin{tabular}{|c|c|c|c|c|c|}
\hline Atom & $\begin{array}{c}\text { Wyckoff } \\
\text { position }\end{array}$ & $x$ & $y$ & $z$ & $U_{\text {eq }}, \AA^{2}$ \\
\hline $\mathrm{Sb}$ & $8 c$ & $0.231111(13)$ & $x$ & $-x$ & $0.01097(7)$ \\
\hline $\mathrm{Cu} 1 / \mathrm{Fe} 1^{\text {a) }}$ & $12 d$ & $1 / 4$ & $1 / 2$ & 0 & $0.00972(11)$ \\
\hline $\mathrm{Cu} 2$ & $24 g$ & $0.01406(18)$ & $x$ & $0.78230(8)$ & $0.0256(5)$ \\
\hline $\mathrm{S} 1$ & $24 g$ & $0.38412(4)$ & $x$ & $0.86277(5)$ & $0.00853(11)$ \\
\hline $\mathrm{S} 2$ & $2 a$ & 0 & 0 & 0 & $0.0137(4)$ \\
\hline
\end{tabular}

a) $\mathrm{The} \mathrm{Cu} / \mathrm{Fe}$ ratio is fixed at $0.83 / 0.17$. See text for details. 
Table 3. Interatomic distances and bond angles

\begin{tabular}{|c|c|c|c|}
\hline Atom-Atom & Distance, $\AA$ & Atom-Atom-Atom & Angles, deg. \\
\hline $\mathrm{Sb}-\mathrm{S} 1$ & $2.4355(6)$ & $\mathrm{S} 1-\mathrm{Sb} 1-\mathrm{S} 1$ & $95.48(2)$ \\
\hline $\mathrm{Sb}-\mathrm{Cu} 2$ & $3.172(3)$ & $\mathrm{S} 1-\mathrm{Cu} 1 / \mathrm{Fe} 1-\mathrm{S} 1$ & $110.977(12)$ \\
\hline $\mathrm{Cu} 1 / \mathrm{Fe} 1-\mathrm{S} 1$ & $2.3146(4)$ & $\mathrm{S} 1-\mathrm{Cu} 1-\mathrm{S} 1$ & $106.50(2)$ \\
\hline $\mathrm{Cu} 2-\mathrm{S} 1$ & $2.2691(8)$ & $\mathrm{S} 1-\mathrm{Cu} 2-\mathrm{S} 1$ & $96.44(5)$ \\
\hline $\mathrm{Cu} 2-\mathrm{S} 2$ & $2.2572(9)$ & $\mathrm{S} 2-\mathrm{Cu} 2-\mathrm{S} 1$ & $130.48(3)$ \\
\hline $\mathrm{Cu} 2-\mathrm{Cu} 2$ & $2.974(3)$ & & \\
\hline
\end{tabular}


Table 4. Parameters of the ${ }^{57} \mathrm{Fe}$ Mössbauer spectra for $\mathrm{Cu}_{12-\mathrm{x}} \mathrm{Fe}_{\mathrm{x}} \mathrm{Sb}_{4} \mathrm{~S}_{13}(x=0.8,1.0,1.2)$ at 300 $\mathrm{K}$

\begin{tabular}{|c|c|c|c|c|c|}
\hline Sample & Subspectrum & $\delta[\mathrm{mm} / \mathrm{s}]$ & $\Delta[\mathrm{mm} / \mathrm{s}]$ & $W[\mathrm{~mm} / \mathrm{s}]^{*}$ & $I[\%]$ \\
\hline \multirow{2}{*}{$\mathrm{Cu}_{11.2} \mathrm{Fe}_{0.8} \mathrm{Sb}_{4} \mathrm{~S}_{13}$} & $\mathrm{Fe} 1$ & $0.19(2)$ & $0.72(3)$ & 0.24 & $16(2)$ \\
\cline { 2 - 6 } & $\mathrm{Fe} 2$ & $0.31(1)$ & $0.28(1)$ & $0.24(2)$ & $84(2)$ \\
\hline \multirow{2}{*}{$\mathrm{Cu}_{11.0} \mathrm{Fe}_{1.0} \mathrm{Sb}_{4} \mathrm{~S}_{13}$} & $\mathrm{Fe} 1$ & $0.17(1)$ & $0.72(3)$ & 0.26 & $15(2)$ \\
\cline { 2 - 6 } & $\mathrm{Fe} 2$ & $0.32(1)$ & $0.28(1)$ & $0.26(1)$ & $85(2)$ \\
\hline \multirow{2}{*}{$\mathrm{Cu}_{10.8} \mathrm{Fe}_{1.2} \mathrm{Sb}_{4} \mathrm{~S}_{13}$} & $\mathrm{Fe} 1$ & $0.14(3)$ & $0.63(3)$ & 0.28 & $17(1)$ \\
\cline { 2 - 6 } & $\mathrm{Fe} 2$ & $0.32(2)$ & $0.27(2)$ & $0.28(1)$ & $83(1)$ \\
\hline
\end{tabular}

(*) values of the relevant parameters were assumed to be equal to each other. 
Table 5. Parameters of the ${ }^{57} \mathrm{Fe}$ Mössbauer spectra for $\mathrm{Cu}_{12-\mathrm{x}} \mathrm{Fe}_{\mathrm{x}} \mathrm{Sb}_{4} \mathrm{~S}_{13}(x=1.5,2.0)$ at $300 \mathrm{~K}$

\begin{tabular}{|c|c|c|c|c|c|c|}
\hline Sample & Subspectrum & $\delta[\mathrm{mm} / \mathrm{s}]$ & $\Delta[\mathrm{mm} / \mathrm{s}]$ & $\begin{array}{c}\omega_{h o p}\left[\mathrm{~s}^{-1}\right] \\
\times 10^{7}\end{array}$ & $n_{\mathrm{Fe}(\mathrm{II})} / n_{\mathrm{Fe}(\mathrm{III})}$ & $I[\%]$ \\
\hline \multirow{4}{*}{$\mathrm{Cu}_{10.5} \mathrm{Fe}_{1.5} \mathrm{Sb}_{4} \mathrm{~S}_{13}$} & $\mathrm{Fe} 1$ & $0.13(1)$ & $0.53(1)$ & - & - & $7(1)$ \\
\hline & $\mathrm{Fe} 2$ & $0.36(1)^{*}$ & $0.22(1)^{*}$ & - & - & $26(1)$ \\
\hline & $\mathrm{Fe} 3$ & $0.57(1)^{* *}$ & $2.57(2) * *$ & - & - & $15(1)$ \\
\hline & Relaxation & $\begin{array}{c}\delta_{\mathrm{Fe}(\mathrm{III})} * \\
\delta_{\mathrm{Fe}(\mathrm{III})} * *\end{array}$ & $\begin{array}{l}\Delta_{\mathrm{Fe}(\mathrm{III})} * \\
\Delta_{\mathrm{Fe}(\mathrm{II})} * *\end{array}$ & $3.03(8)$ & $1.12(4)$ & $52(2)$ \\
\hline \multirow{4}{*}{$\mathrm{Cu}_{10} \mathrm{Fe}_{2} \mathrm{Sb}_{4} \mathrm{~S}_{13}$} & Fe1 & $0.14(3)$ & $0.56(1)$ & - & - & $7(2)$ \\
\hline & $\mathrm{Fe} 2$ & $0.39(2)$ & $0.23(1)$ & - & - & $7(1)$ \\
\hline & $\mathrm{Fe} 3$ & $0.60(2)$ & $2.82(2)$ & - & - & $54(1)$ \\
\hline & Relaxation & $\begin{array}{c}\delta_{\mathrm{Fe}(\mathrm{III})} * \\
\delta_{\mathrm{Fe}(\mathrm{III})} * *\end{array}$ & $\begin{array}{l}\Delta_{\mathrm{Fe}(\mathrm{III})} * \\
\Delta_{\mathrm{Fe}(\mathrm{II})} * *\end{array}$ & $5.64(6)$ & $2.63(2)$ & $32(2)$ \\
\hline
\end{tabular}

$(*),(* *)$ values of the relevant parameters were assumed to be equal to each other. 
Table 6. Parameters of the ${ }^{57} \mathrm{Fe}$ Mössbauer spectra for $\mathrm{Cu}_{12-\mathrm{x}} \mathrm{Fe}_{\mathrm{x}} \mathrm{Sb}_{4} \mathrm{~S}_{13}(x=1.5,2.0)$ at $77 \mathrm{~K}$

\begin{tabular}{|c|c|c|c|c|c|}
\hline Sample & Subspectrum & $\delta[\mathrm{mm} / \mathrm{s}]$ & $\Delta[\mathrm{mm} / \mathrm{s}]$ & $W[\mathrm{~mm} / \mathrm{s}]$ & $I[\%]$ \\
\hline \multirow{3}{*}{$\mathrm{Cu}_{10.5} \mathrm{Fe}_{1.5} \mathrm{Sb}_{4} \mathrm{~S}_{13}$} & $\mathrm{Fe} 1$ & $0.25(2)$ & $0.91(2)$ & $0.29^{*}$ & $9(3)$ \\
\cline { 2 - 6 } & $\mathrm{Fe} 2$ & $0.44(1)$ & $0.27(1)$ & $0.29(1)^{*}$ & $51(3)$ \\
\cline { 2 - 6 } & $\mathrm{Fe} 3$ & $0.72(2)$ & $2.92(2)$ & $0.29^{*}$ & $40(1)$ \\
\hline \multirow{2}{*}{$\mathrm{Cu}_{10} \mathrm{Fe}_{2} \mathrm{Sb}_{4} \mathrm{~S}_{13}$} & $\mathrm{Fe} 1$ & $0.25(3)$ & $0.91(1)$ & $0.27^{*}$ & $7(2)$ \\
\cline { 2 - 6 } & $\mathrm{Fe} 2$ & $0.43(1)$ & $0.21(2)$ & $0.35(4)$ & $17(2)$ \\
\cline { 2 - 6 } & $\mathrm{Fe} 3$ & $0.73(2)$ & $3.04(2)$ & $0.27(2)^{*}$ & $76(1)$ \\
\hline
\end{tabular}

(*) values of the relevant parameters were assumed to be equal to each other. 


\section{Figure Captions}

Figure 1. Unit cell parameter $a(\AA)$ as a function of $\mathrm{Fe}$ content in $\mathrm{Cu}_{12-\mathrm{x}} \mathrm{Fe}_{\mathrm{x}} \mathrm{Sb}_{4} \mathrm{~S}_{13}$. Note that the size of the error bar is smaller than the size of the circle representing the unit cell value.

Figure 2. Crystal structure of $\mathrm{Cu}_{11.0} \mathrm{Fe}_{1.0} \mathrm{Sb}_{4} \mathrm{~S}_{13}$.

Figure 3. Variants of $\mathrm{Cu} 2-\mathrm{Sb}$ contacts (shown in orange) in the crystal structure of $\mathrm{Cu}_{11.0} \mathrm{Fe}_{1.0} \mathrm{Sb}_{4} \mathrm{~S}_{13}$. The central part shows close-lying split $\mathrm{Cu} 2$ atoms. Labels under the figures are the numbers of the $\mathrm{Sb}-\mathrm{Cu} 2$ bonds for each $\mathrm{Sb}$ atom in a cluster.

Figure 4. ${ }^{57} \mathrm{Fe}$ Mössbauer spectra for $\mathrm{Cu}_{12-\mathrm{x}} \mathrm{Fe}_{\mathrm{x}} \mathrm{Sb}_{4} \mathrm{~S}_{13}$ with $x=0.8,1.0$, and 1.2 at $300 \mathrm{~K}$

Figure 5. ${ }^{57} \mathrm{Fe}$ Mössbauer spectra for $\mathrm{Cu}_{12-\mathrm{x}} \mathrm{Fe}_{\mathrm{x}} \mathrm{Sb}_{4} \mathrm{~S}_{13}$ with $x=1.5$ and 2.0 at $300 \mathrm{~K}$

Figure 6. ${ }^{57} \mathrm{Fe}$ Mössbauer spectra for $\mathrm{Cu}_{12-\mathrm{x}} \mathrm{Fe}_{\mathrm{x}} \mathrm{Sb}_{4} \mathrm{~S}_{13}$ with $x=1.5$ and 2.0 at $77 \mathrm{~K}$

Figure 7. Electron exchange scheme. $U_{0}$ is a potential well difference and $\mathrm{E}_{\mathrm{A}}$ is the intervening potential barrier. See text for explanations.

Figure 8. Inverse magnetic susceptibility $(1 / \chi)$ versus temperature $(T)$ at $5 \mathrm{~T}$ external field for $\mathrm{Cu}_{12-\mathrm{x}} \mathrm{Fe}_{\mathrm{x}} \mathrm{Sb}_{4} \mathrm{~S}_{13}$ with $x=0.8,1.0,1.2$, and 1.5. 


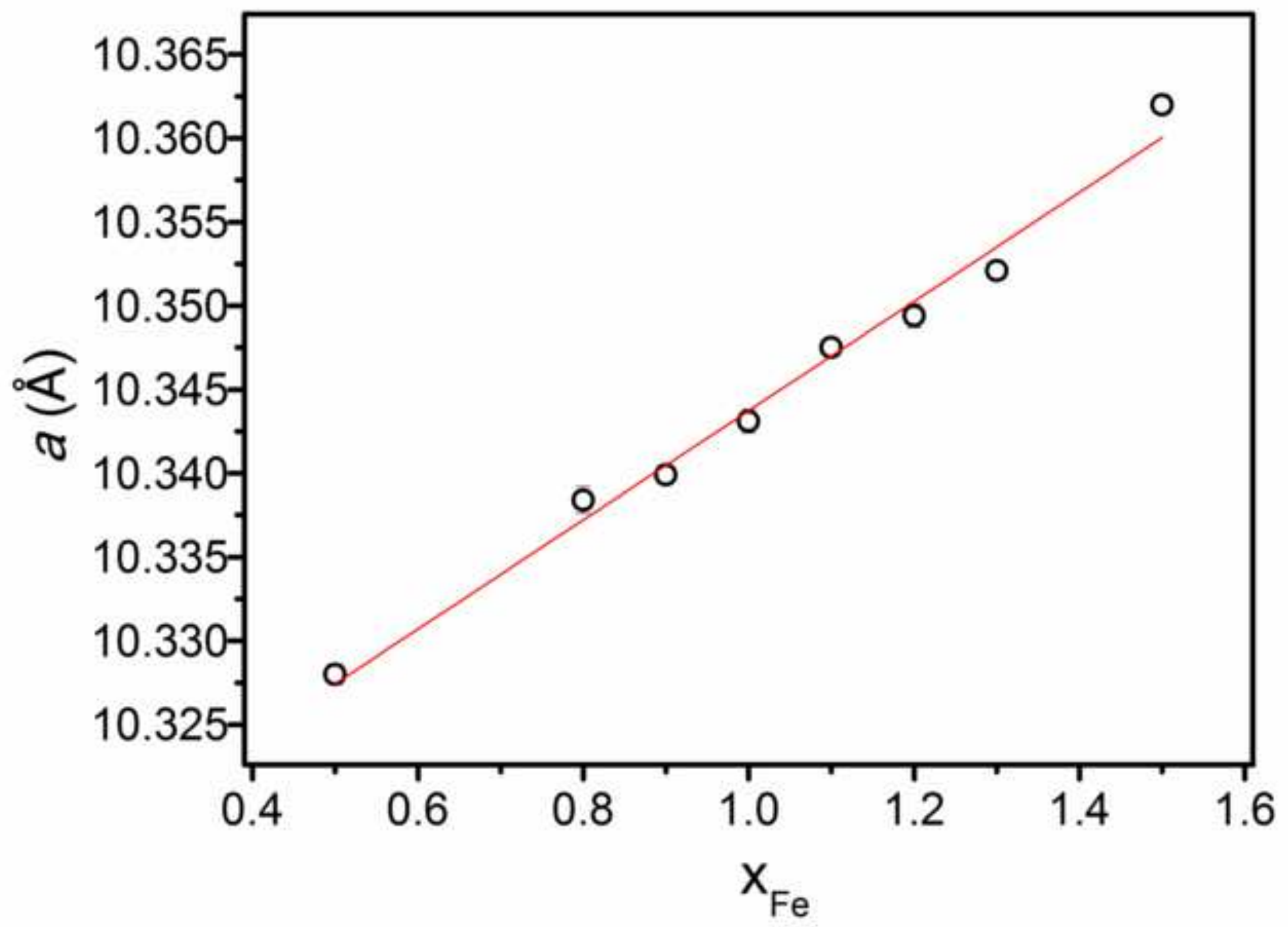



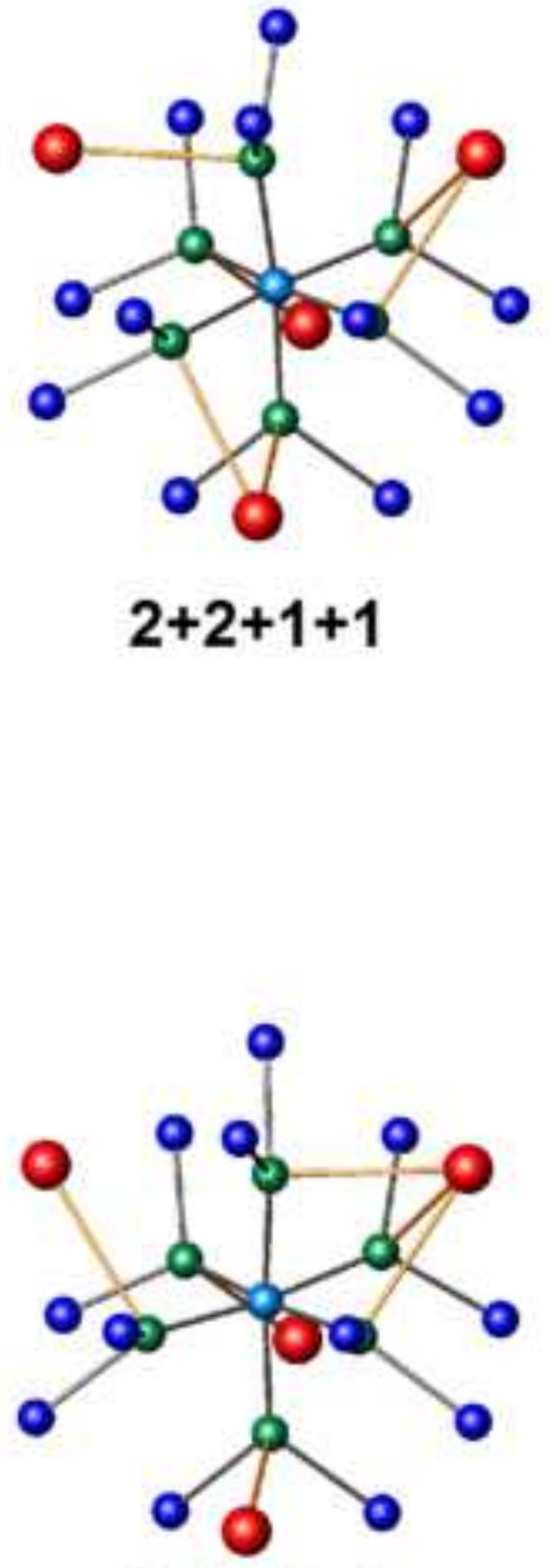

$3+1+1+1$
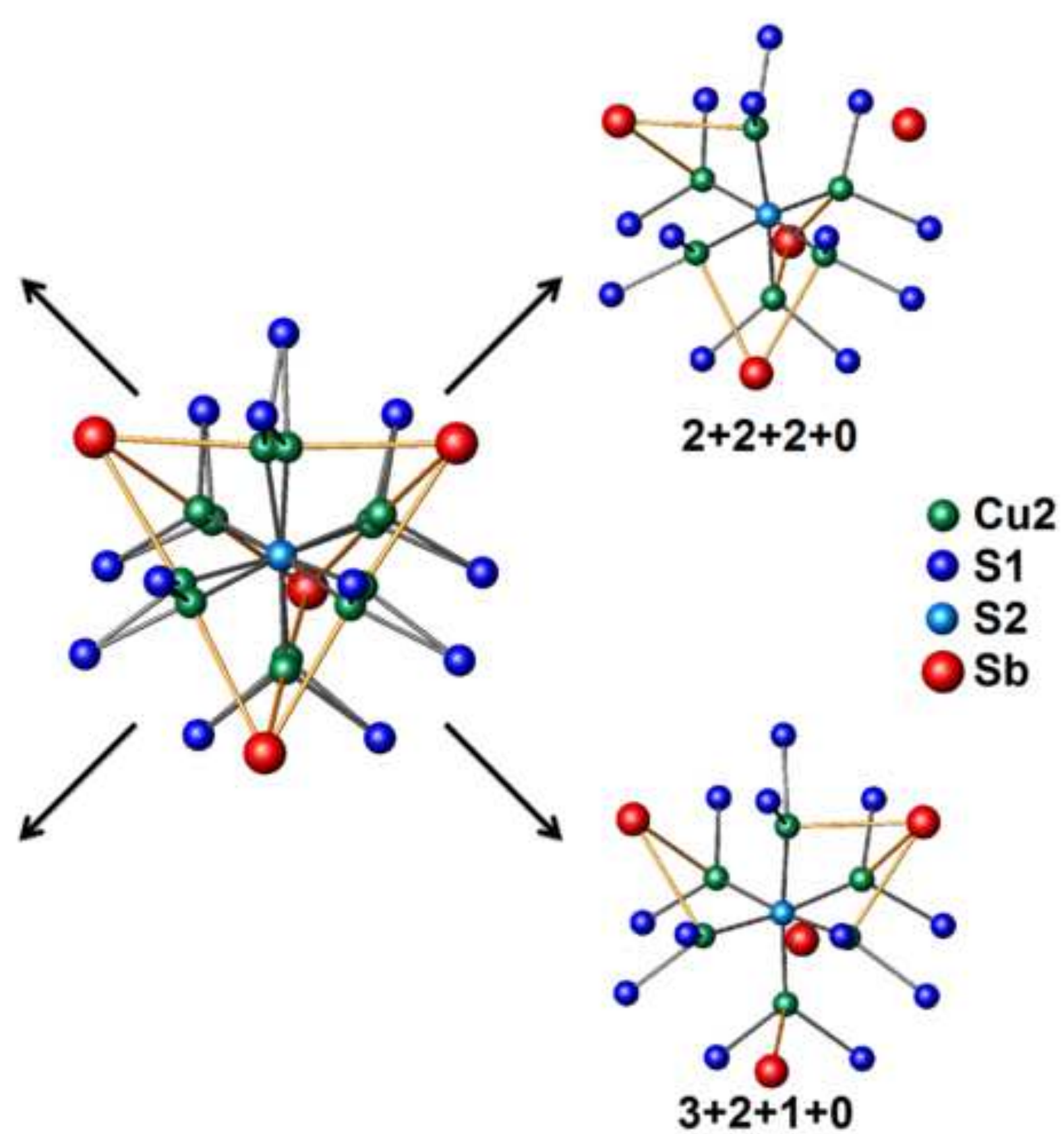


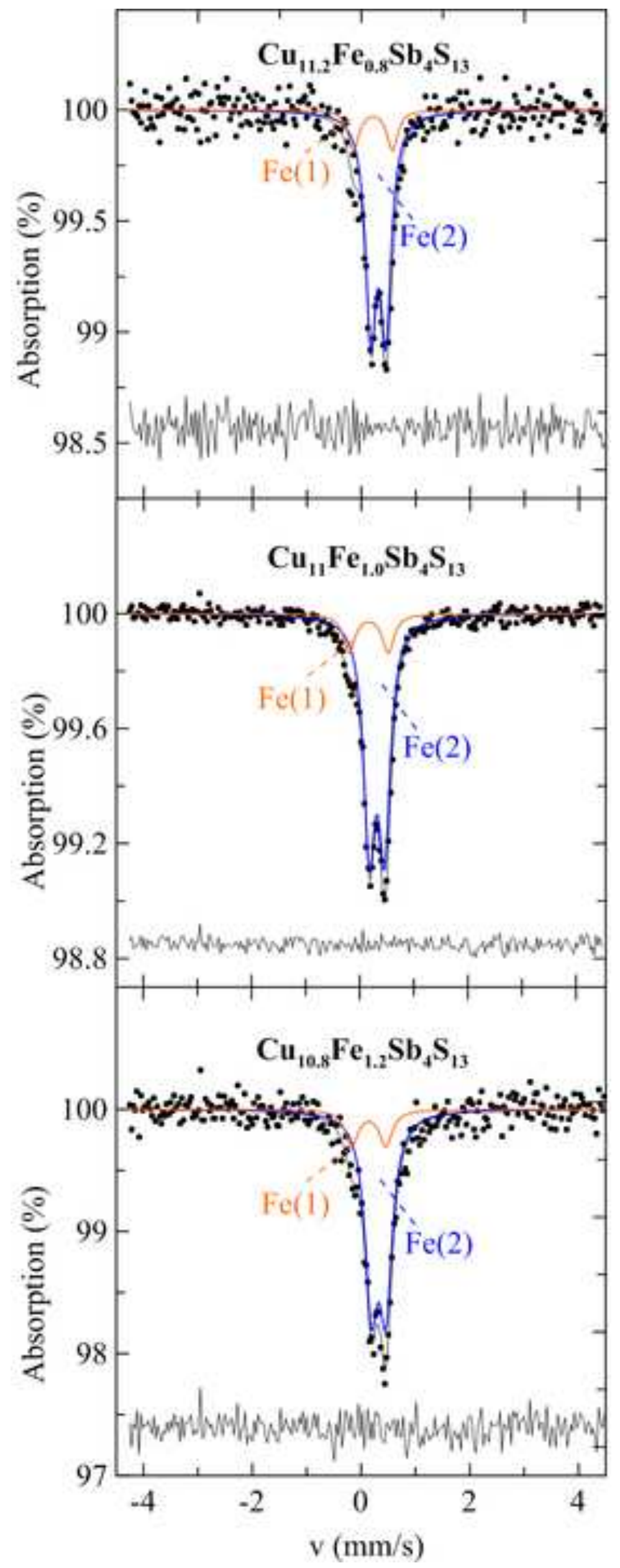




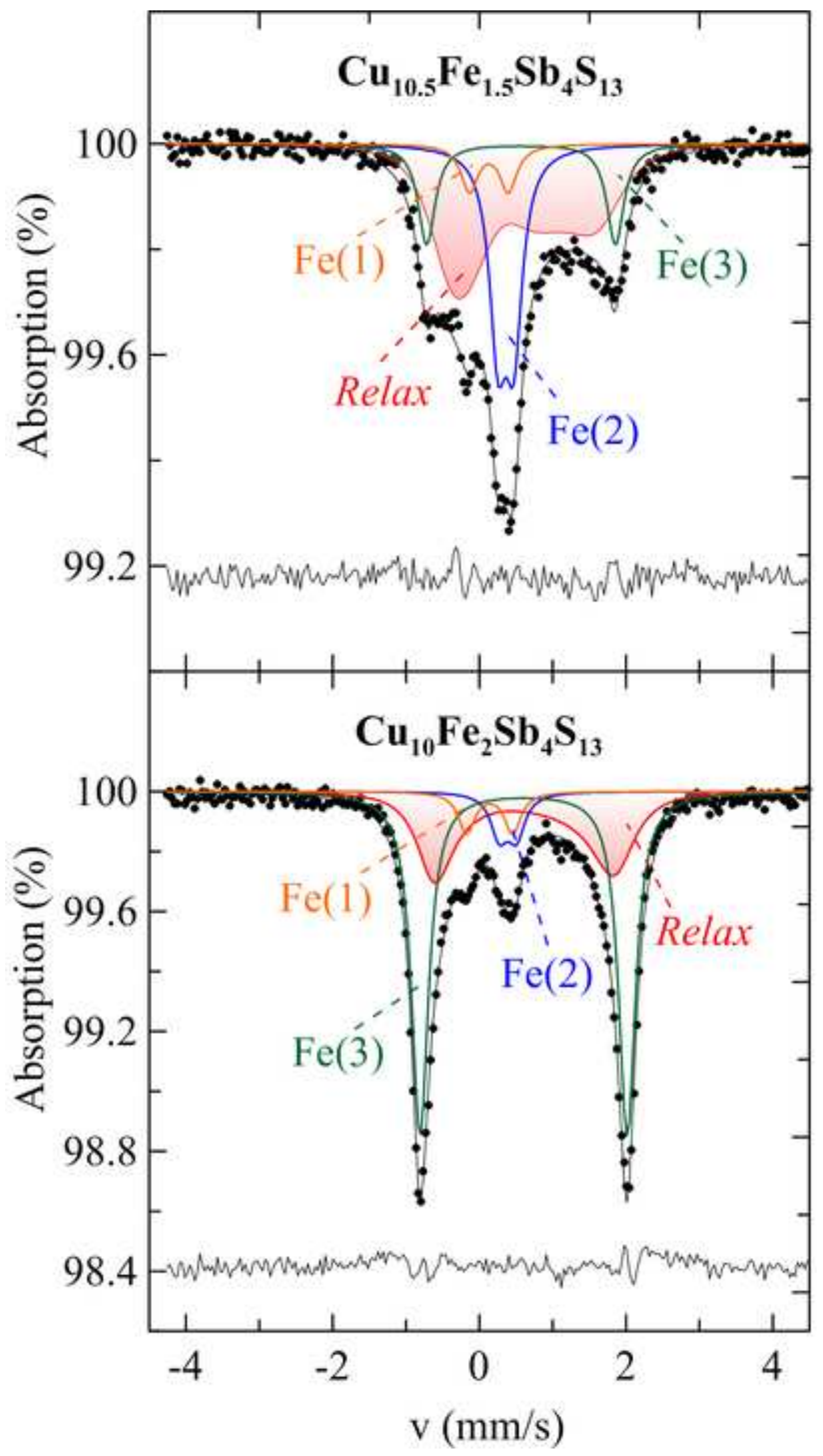




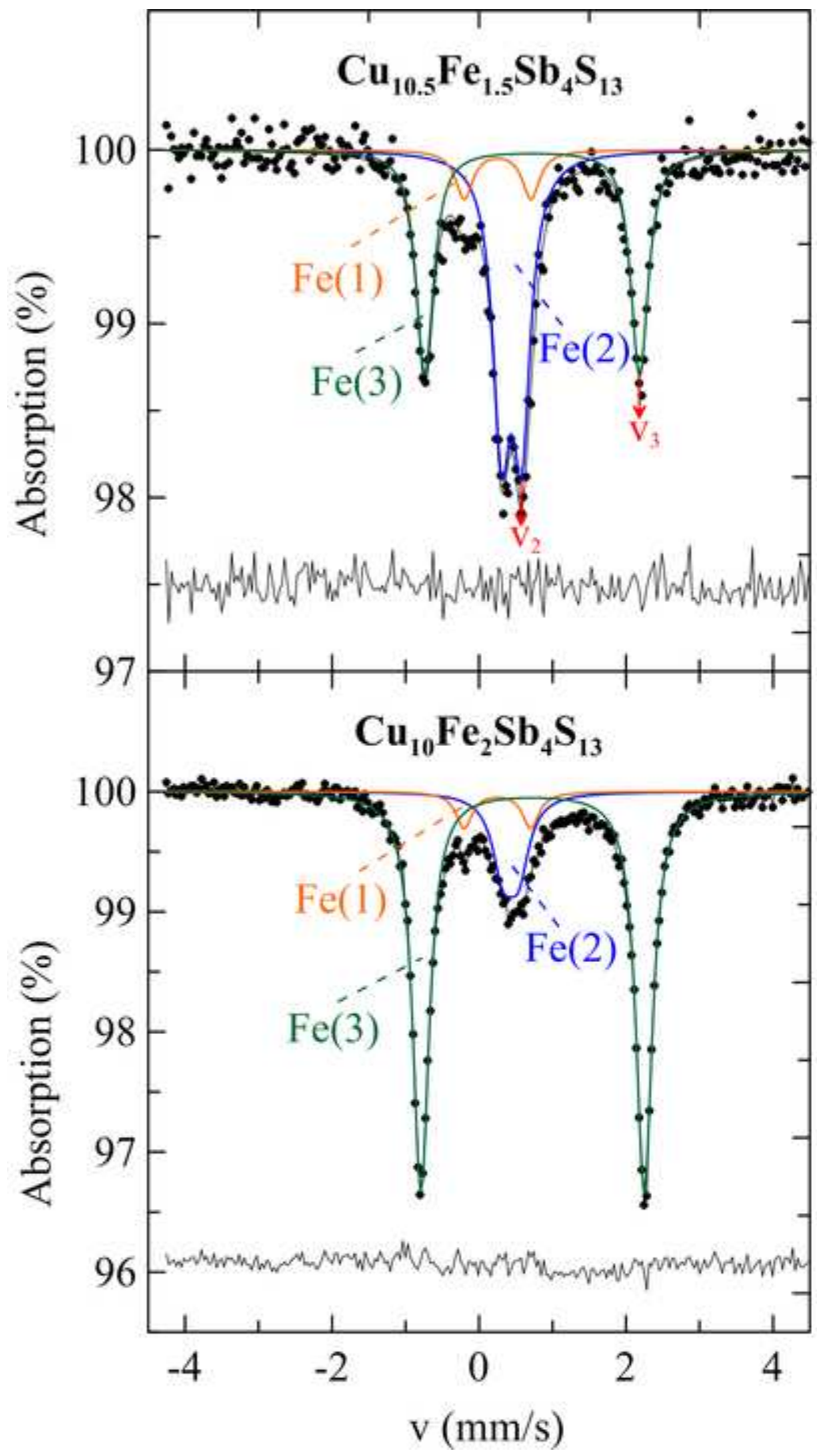




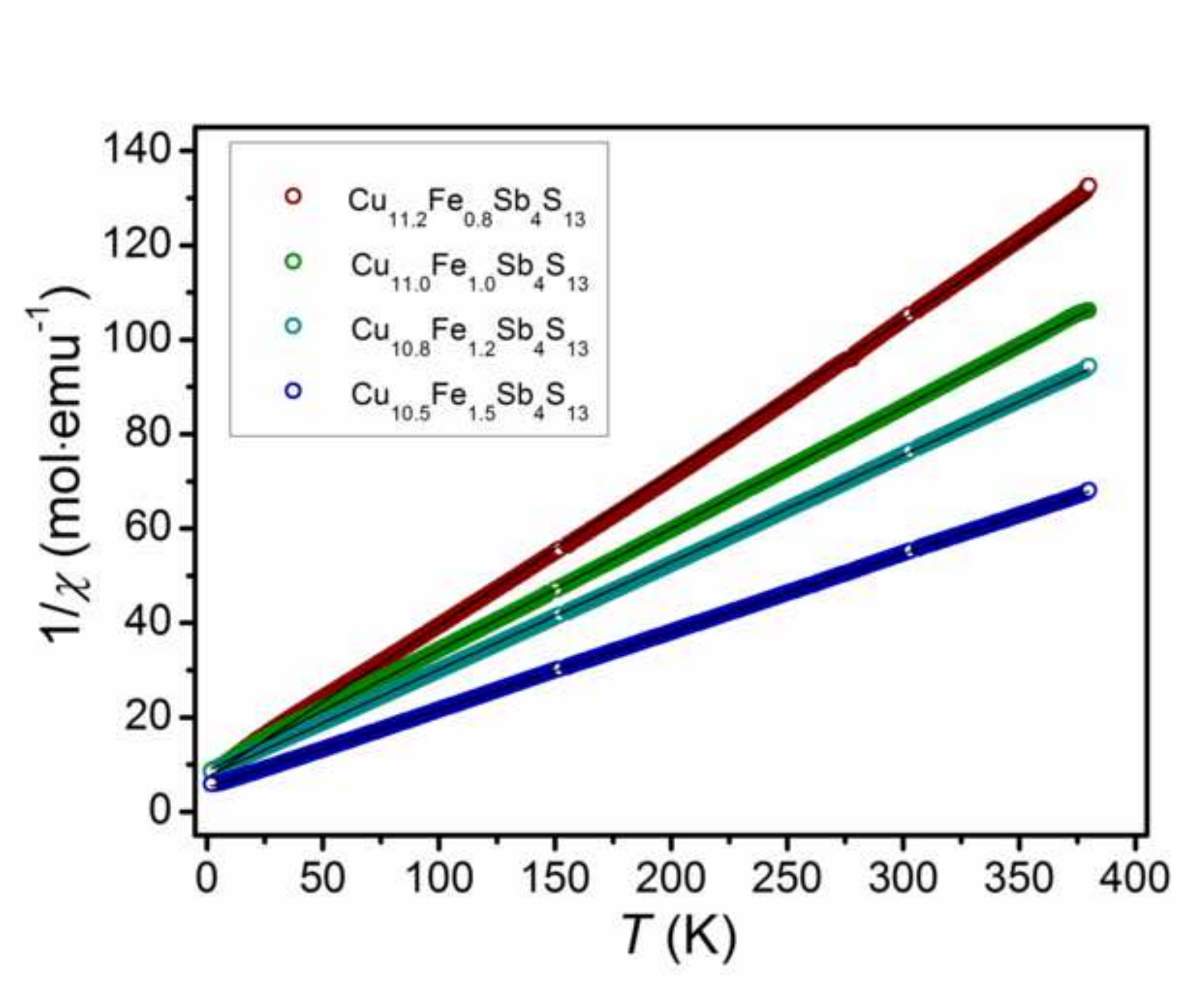

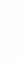

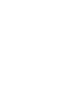

8

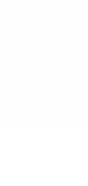



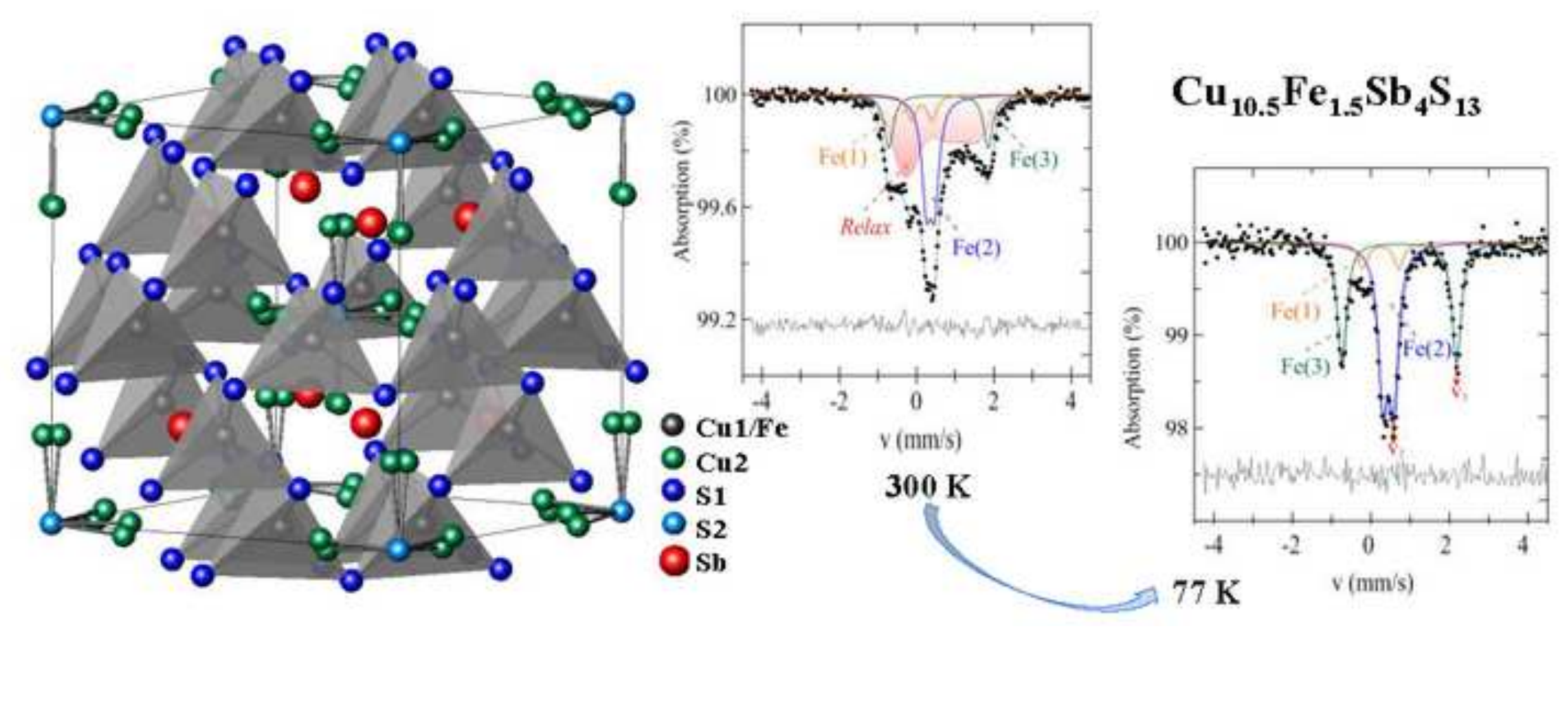

$\Rightarrow 77 \mathrm{~K}$

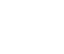

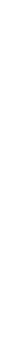

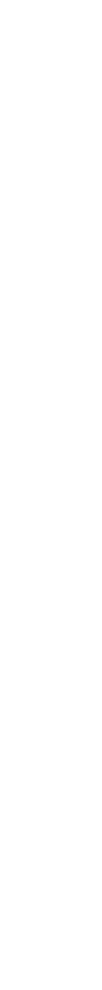

(


Graphical Abstract Legend (TOC Figure)

Synthetic iron-containing tetrahedrites, $\mathrm{Cu}_{12-\mathrm{x}} \mathrm{Fe}_{\mathrm{x}} \mathrm{Sb}_{4} \mathrm{~S}_{13}$, display a variable valence state and role of iron. At low iron content two nonequivalent and non-interacting $\mathrm{Fe}^{3+}$ cations occur. At higher levels of substitution, room-temperature Mössbauer spectra indicate the electron hopping between part of $\mathrm{Fe}^{3+}$ and $\mathrm{Fe}^{2+}$ centers, which freezes out upon cooling down to $77 \mathrm{~K}$, whereas the rest of iron atoms exists as valence-localized $\mathrm{Fe}^{3+}$ and $\mathrm{Fe}^{2+}$ cations. 